\title{
Protective Effects of Vitamin C against Nicotine-Induced Oxidative Damage of Rat Liver and Kidney
}

\author{
Ghada S. Mahmoud ${ }^{1}$, Ayman S. Amer ${ }^{2}$ \\ ${ }^{1}$ Department of Human Physiology, ${ }^{2}$ Departments of Human Anatomy and Embryology \\ Faculty of Medicine, Assiut University, Assiut, Egypt
}

\begin{abstract}
:
Objective: Vitamin $C$ is a vital antioxidant that may antagonize deleterious effects of smoking. The aim of this study was to evaluate the effects of administration of nicotine alone for three weeks or combined with vitamin $C$ on the antioxidant defense status, functional, histopathological changes, and immunohistochemical demonstration of proliferating cell nuclear antigen (PCNA) in rat liver and kidney tissues.

Methods: Animals were divided into four groups; (C) saline-treated, (VC) vitamin C-treated, (NIC) nicotinetreated, all were for 3 weeks, and $(N I C+V C)$ is given vitamin $C$ for 3 days prior, with nicotine injection and 2 days thereafter.

Results: Present work showed that nicotine exposure caused significant reduction in total body weight, relative liver and kidney weights, elevated malondialdehyde (MDA), alanine transaminase (ALT), aspirate transaminase $(A S T)$, and alkaline phosphatase (ALP) in both hepatic and renal tissues. Co-exposure to nicotine and vitamin $C$ maintained normal liver and kidney weight, significantly lowered MDA, ALT, AST, ALP and elevated glutathione in both hepatic and renal tissues compared NIC group as well as controls. Nicotine administration resulted in shedding, necrosis, and loss of brush border of cells covering proximal and distal convoluted tubules of kidney. The liver in the nicotine-treated group showed vacuolated cytoplasm of hepatocytes, with dilated central vein and sinusoids and mitochondrial destruction. Immunohistochemistry showed dense PCNA immunostaining in the livers of nicotine-treated rats. Vitamin $C$ induced partial correction of nicotine-induced histopathological damage of liver and kidney and significant elevation in PCNA expression.
\end{abstract}

Conclusion: The results of present work suggested that vitamin $C$ has a promising prophylactic effect against nicotine-induced oxidative damage of liver and kidney.

Keywords: Nicotine, Vitamin C, Ascorbic acid, Liver, Kidney, Histopathology, Glutathione (GSH),

Malondialdehyde (MDA), Lipid peroxidation, Oxidative stress, Immunohistochemistry.

\section{Introduction}

Tobacco smoking is the most socially spread habit and is considered as one of the leading causes of premature death in developed as well as developing countries. Epidemiological studies have shown that cigarette smoking may accelerate the progression of renal, pulmonary, and cardiac fibrosis [1], but whether it might cause organ damage in rather healthy tissues is an important question. The bad effects of nicotine on body function such as rise in heart rate, blood pressure, disturbed lipid profile, atherosclerosis and ischemic heart disease [2] had been previously shown by direct administration of nicotine in human and animals [3]. However, the mechanisms underlying these effects need to be elucidated. Nicotine as major constituent of tobacco is probably the cause of the smoking-induced organ malfunction. Cotinine, the major metabolite of nicotine is produced by $\mathrm{C}$-oxidation pathway in the liver and has been used as a marker for nicotine intake [4]. Kidney is probably the organ responsible for getting rid of cotinine produced by the liver. To this end, this work is planned to investigate the functional and structural effects of nicotine administration for three weeks on rat liver and kidney.

The role of oxidative stress in the pathogenesis of liver damage is supported by previous studies. It has been shown that nicotine enhanced lipid peroxidation and the production of reactive oxygen species [5]. A fairly recent study reported that nicotine enhanced the activity of NADPH oxidase as well as myeloperoxidase activity in murine peritoneal macrophages [6]. Other studies reported malfunction of antioxidant defense systems through the reduction of the activity of catalase and superoxide dismutase [7]. Vitamin C or L-ascorbic acid is vital dietary supplement that has antioxidant properties. Most of the protective antioxidant effect of ascorbate is due to its action as an electron donor that undergoes $\mathrm{pH}$-dependent oxidation producing hydrogen peroxide [8]. Recent studies showed that parentral administration of vitamin $\mathrm{C}$ through escaping the gut control and reaching very high level in plasma is more effective in antagonizing oxidants [9]. The risk of oxidative stress mainly affect liver and kidney tissues therefore, we investigated the effect of nicotine injection (i.p.) for three weeks or combined with vitamin $\mathrm{C}$ on lipid peroxidation and glutathione level in hepatic and renal tissues. 
Proliferating cell nuclear antigen (PCNA), an S-phase marker, is considered as the maestro of the replication fork and is known as the sliding clamp [10]. PCNA is formed of alpha and beta protein assembled into a multimers that encircles the DNA double helix at the replication fork as DNA polymerase adds nucleotides to the growing strand [11]. It also attaches to the DNA polymerase by protein/protein interaction and slides along the DNA with the advancing polymerase therefore, increasing the number of nucleotides that the polymerase can add up to 1,000-fold [12]. However, PCNA expression in non-proliferating cells is associated with repair of DNA damage [13]. In this concern, Kaya and his group reported that proteins associated with DNA damage and repair (p53, Bax, PCNA) were highly expressed in the nuclei of apoptotic and injured cells which showed DNA fragmentation [14]. This study was designed to examine the role of i.p. administration of nicotine for three weeks or combined with vitamin $\mathrm{C}$ on the oxidative status, functional, structural changes, and regeneration capacity of the liver and kidney tissues of young adult male rats. We assessed the damage and regenerative capacity of the liver and kidney tissues by immunohistochemical staining of PCNA.

\section{Material and Methods}

\section{II.1 Drugs and chemicals}

Nicotine: Synonyms 3-(1-Methyl-2-pyrrolidinyl) pyridine, (S)-(-)-Nicotine $100 \%$ concentration (Cat.No. 109535, Product number: 8208770025, glass bottle $(25 \mathrm{ml})$ was obtained from Merck KGaA Frankfurter Str. 250, 64293 Darmstadt Germany. Vitamin C 1 gm/ 5ml ampoule (Batch No.: 213145, Memphis Co. For Pharm. \& Chem. Ind. Cairo-Egypt).

\section{II.2 Animal preparation and experimental approach}

A total of 24 young adult male Albino rats weighing 150-200 g were used. For acclimatization, rats were kept for 3 days before the onset of experiment and housed in metal cages at room temperature $25^{\circ} \mathrm{C}, 12$ hours light dark cycle in the research laboratory of the department of Human Anatomy and Embryology, Faculty of Medicine-Assiut University during the period of the research. Water and food (standard rat chow) were allowed to rats ad libitum. The experiments were carried out according to the protocol approved by the Local Ethical Committee of the Faculty of Medicine, Assiut University in accordance with the ethical guidelines for scientific research in conscious animals.

Animals were divided into four groups (6 rats each). Group I (C) serve as control receive i.p. injection of saline daily for 3 weeks. Group II (VC) is given vitamin C $300 \mathrm{mg} / \mathrm{kg}$ i.p. for 3 weeks. Group III (NIC) is given nicotine $5 \mathrm{mg} / \mathrm{kg}$ i.p. for 3 weeks. Group IV (NIC+VC) is given vitamin C $300 \mathrm{mg} / \mathrm{kg}$ i.p. for 3 days prior, with nicotine injection and 2 days thereafter. Rats in all groups were anaesthetized with ether, scarified by decapitation 24hours after the last injections. Target tissues (kidney and liver) were excised from animals at the time of sacrifice, cleared off blood and immediately transferred to ice-cold containers containing $0.9 \%$ sodium chloride for various estimations.

\section{II.3 Preparation of tissue extracts}

Livers and kidney were excised immediately, washed with ice-cold physiologic saline solution $(0.9 \%)$, dried and weighed. Approximately 0.5 gm of livers and kidneys tissues was homogenized in 10 volumes (1:10; w/v) of ice-cold isotonic saline $(0.9 \% \mathrm{NaCl}, \mathrm{pH} 7.4)$ in an Ultra Turrax tissue homogenizer for 30s. For detection of MDA; homogenates were centrifuged at $10000 \mathrm{rpm}$ for $10 \mathrm{~min}$. The supernatant was immediately pipetted into clean centrifuge tubes and stored in aliquots $\left(-80^{\circ} \mathrm{C}\right)$ for analysis. For detection of $\mathrm{GSH}$; homogenates were mixed with an equal volume of $1 \mathrm{~mole} / \mathrm{L}$ perchloric acid and mixed by vortex. Then, the mixture was allowed to stand at room temperature for $5 \mathrm{~min}$. The supernatant was collected carefully without disturbing the precipitate into clean centrifuge tubes and stored in aliquots $\left(-20^{\circ} \mathrm{C}\right)$ until assay.

\section{II.4 Oxidative stress parameters}

\section{II.4.1 Determination of liver and kidney lipid peroxidation}

It is estimated by measuring the thiobarbituric acid reactive substance (TBARS) i.e. malondialdehyde (MDA) in liver and kidney homogenates according to the method of [13]. MDA forms a 1:2 adduct with thiobarbiturique acid (TBA) which can be measured by spectrophotometry. Briefly, $0.2 \mathrm{ml}$ of standards or tissue homogenate was added to $0.2 \mathrm{ml}$ of $8.1 \%$ of sodium doedecyl sulfate, then $1.5 \mathrm{ml}$ of $20 \%$ acetic acid, last, $1.5 \mathrm{ml}$ of $0.8 \%$ TBA freshly prepared in solution (bidistilled water in the presence of $0.1 \mathrm{M} \mathrm{NaOH}$ freshly prepared) were added. The mixture was diluted to $4 \mathrm{ml}$ by addition of bidistilled water. After vortex, the mixture is incubated in $\mathrm{H} 2 \mathrm{O}$ bath at $95^{\circ} \mathrm{C}$ for $60 \mathrm{~min}$. After cooling in a cold water bath for $10 \mathrm{~min}$, the mixture is extracted with $4 \mathrm{ml}$ of $\mathrm{n}$-butanol and pyridine (1.5:1 v/v) by vigorous shaking. After centrifugation for $10 \mathrm{~min}$, the organic phase is collected and the absorbance is measured at a wave length of $532 \mathrm{~nm}$. The concentration of MDA was calculated by drawing standard curve (Fig. 1A) using GraphPad Prism 5 software and expressed in micromoles per gram of kidney or liver tissue. 


\section{II.4.2 Determination of liver and kidney glutathione (GSH) levels}

The sulfhydryl group of GSH reacts with 5,5-dithiobis-2-nitro-benzoic acid (DTNB or Ellman's Reagent) and produces a yellow colored 5-thio-2-nitrobenzoic acid (TNB). GSH level in liver and kidney homogenate was measured according to the method of Ohkawa and his group [15]. In brief, before the assay the $\mathrm{pH}$ of homogenate was adjusted by adding $50 \mu \mathrm{l}$ of $4 \mathrm{~mol} / \mathrm{L}$ triethanolamine/ $1 \mathrm{ml}$ of the supernatant and vortex immediately. Then, pipette successively into clean test tubes $200 \mu \mathrm{l}$ of the samples or standards, $200 \mu \mathrm{l}$ bidistilled water, $2 \mathrm{ml}$ saline, $1 \mathrm{ml}$ DTNB, then, mix and vortex. The absorbance was measured at a wave length of $412 \mathrm{~nm}$. The concentration of MDA was calculated by drawing standard curve (Fig. 1B) using GraphPad Prism 5 software and expressed in micromoles per gram of kidney or liver tissue.

\section{II.5 Determination of alanine transaminase, aspartate transaminase, and alkaline phosphatase in liver homogenates}

Alanine aminotransferase (ALT) was estimated in liver homogenate by using Alanine aminotransferase (EC 2.6.1.2) liquiUV test (diagnostic kits ordered from Human Gesellschaft für Biochemica und Diagnostica $\mathrm{mbH}$, Wiesbaden, Germany) following the manufacture instructions. Aspartate aminotransferase (AST) was estimated in liver homogenate by using Aspartate aminotransferase (EC 2.6.1.1) liquiUV test (diagnostic kits ordered from Human Gesellschaft für Biochemica und Diagnostica mbH, Wiesbaden, Germany) following the manufacture instructions. Alkaline phosphatase (ALP) was estimated in liver homogenates by using Alkaline phosphatase FS DGKC, Diagnostic reagent for quantitative in vitro determination of alkaline phosphatase on photometric system, Cat No. 8440401100200 (diagnostic kits ordered from DiaSys Diagnostic Systems $\mathrm{GmbH}$, Alte Strasse 965558 Holzheim Germany) following the manufacture instructions.

\section{II.6 Immunohistochemistry and light microscopy}

The specimens were taken from the kidney and liver of each group and were fixed in $10 \%$ neutralbuffered formalin solution, dehydrated in ascending grades of alcohol, cleared, embedded in paraffin [16]. Paraffin sections were cut at $6 \mu \mathrm{m}$ and mounted on aminopropyltriethoxysilaine (APES)-coated slides. To eliminate the endogenous peroxidase activity the sections were incubated in $0.3 \% \mathrm{H}_{2} \mathrm{O}_{2}$ for 30 min. Antigen retrieval (unmasking) was done by heating slides in sodium citrate buffer $(\mathrm{pH} 6.0)$ at $95^{\circ} \mathrm{C}$ in a microwave for $15 \mathrm{~min}$ and slowly cooling to room temperature [17]. Sections were then incubated for $24 \mathrm{~h}$ at $4^{\circ} \mathrm{C}$ with the primary antibody [Rabbit polyclonal antibody directed against proliferating cell nuclear antigen, PCNA (Thermo Scientific, South San Francisco, California, USA; dilution 1:100)]. Immunohistochemical reaction was detected by using the standardized commercially available UltraVision Detection System anti-polyvalent HRP/DAB kit (Thermo Fisher scientific, USA). The slides were washed and incubated with biotinylated goat anti-polyvalent (goat anti-rabbit secondary antibody, dilution 1:200) for $10 \mathrm{~min}$ at room temperature. Then sections were incubated with streptavidin peroxidase for $10 \mathrm{~min}$ and finally with $0.05 \%$ diaminobenzidine (DAB) plus chromogen for 15 min. Slides were counterstained with Hematoxylin and Eosin (H\&E), dehydrated, cleared, and mounted. PCNA-positive cells appeared with brown nuclei. Negative control slides were prepared by incubating the slides without the primary antibody; hence, no immunostaining occurred [18]. Slides were examined using an Olympus CX41 optical microscope equipped with an Olympus EVOLT E-330 digital camera interfaced to a computer.

\section{7 Transmission electron microscopy}

Liver and kidney specimens were fixed in 5\% cacodylated-buffered glutaraldehyde for $24 \mathrm{~h}$ and

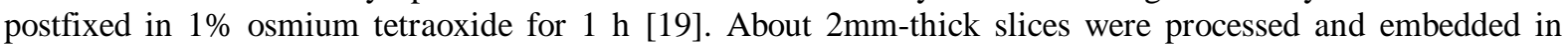
Epon-araldite mixture. Semithin sections of $1 \mu \mathrm{m}$ thickness were cut with a glass knife in KLB, Bromma Ultramicrotome, and stained with toluidine blue and examined. Ultrathin sections (450-500 A) from liver selected areas were cut with ultramicrotome, mounted on copper grids, stained with uranyl acetate and lead citrate, examined with a transmission electron microscope model JEM100CXII (JEOL, Tokyo, Japan), and photographed in the Assiut University Electron Microscopy Unit.

\section{II.8 Statistical analysis}

GraphPad Prism 5 (GraphPad Software Inc., La Jolla, CA, USA) was used for data analysis. Data were presented as mean +/-SE. Comparison among groups is done using One-Way Analysis of Variance (ANOVA) followed by Bonferroni Multiple comparison posthoc test. A (P) value of less than 0.05 was considered to represent a statistically significant difference. 


\begin{abstract}
III. Results
III. 1 Effect of nicotine versus nicotine and vitamin C on Malondialdehyde (MDA) concentration in renal and hepatic tissues of rats

Treatment with nicotine $5 \mathrm{mg} / \mathrm{kg}$ i.p. daily for 3 weeks caused significant rise in MDA levels in both renal and hepatic tissues of rats compared to both saline- treated and vitamin C-treated groups. Coadministration of nicotine and vitamin C caused significant reduction in MDA level in renal and in hepatic tissue compared to nicotine treated group. Insignificant difference in MDA levels in renal tissue was found between saline-treated $(\mathrm{C})$, vitamin $\mathrm{C}$-treated groups $(\mathrm{VC})$, or nicotine and vitamin C-treated group (NIC+VC). Significant rise in MDA levels was found nicotine + vitamin C group compared to both saline-treated and vitamin $\mathrm{C}$-treated groups indicating that vitamin $\mathrm{C}$ provide partial protection against oxidative stress in liver tissues. Insignificant difference in renal or hepatic MDA levels was found between saline-treated, vitamin Ctreated groups (Fig. 2A \& B. $n=6$ ).
\end{abstract}

\title{
III. 2 Effect of nicotine versus nicotine and vitamin C on glutathione (GSH) concentration in renal tissues of rats
}

Treatment with nicotine $5 \mathrm{mg} / \mathrm{kg}$ i.p. daily for 3 weeks caused insignificant change in GSH levels in renal and hepatic tissues of rats compared to saline- treated and vitamin C-treated groups. Co-administration of nicotine and vitamin $\mathrm{C}$ caused significant rise in GSH level in both renal and hepatic tissues compared to nicotine treated group and compared to both saline-treated and vitamin $\mathrm{C}$-treated groups (Fig. 3A \& B, n=6).

\section{III.3 Effect of nicotine versus nicotine and vitamin $\mathrm{C}$ on relative kidney and liver weight compared to total body weight of rats \\ Treatment with nicotine $5 \mathrm{mg} / \mathrm{kg}$ i.p. daily for 3 weeks caused significant reduction of relative kidney weights of rats compared to saline- treated group. Treatment with nicotine also caused significant reduction of relative liver weight and total body weight of rats compared to both saline- treated and vitamin C-treated groups. Co-administration of nicotine and vitamin $\mathrm{C}$ caused significant increase in relative kidney and liver weight compared to nicotine treated group but failed to correct the decrease in total body weight. Insignificant difference in relative kidney and liver weight between other groups was found. (Fig. 4A, B \& C, n=6).}

III.4 Effect of nicotine versus nicotine and vitamin $\mathrm{C}$ on alanine transaminase (ALT), aspartate transaminase (AST), and alkaline phosphatase (ALP):

Treatment with nicotine $5 \mathrm{mg} / \mathrm{kg}$ i.p. daily for 3 weeks caused significant rise in ALT, AST, and ALP level in liver homogenate. Co-administration of nicotine and vitamin $\mathrm{C}$ caused significant reduction in ALT, AST, and ALP level compared to nicotine-treated group $(\mathrm{P}<0.05)$. Insignificant difference of ALT and AST level between other groups was found. Significant decrease in ALP level in VC treated group compared to control (Fig. 4 D \& E, F, n=8).

\section{III.5 Histological analysis of the liver tissues: \\ III.5.1 Light microscopy \\ III.5.1.1 Semithin sections}

In the control group rat livers of the present study the hepatic lobules consisted of a central vein with plates of hepatocytes radiating from the center toward the periphery (Fig. 5.1). The hepatocytes were polyhedral in shape with centrally located rounded vesicular nuclei and intracytoplasmic basophilic bodies. Blood sinusoids were observed between the hepatocytes, and Kupffer cells (sinusoidal stellate macrophages) were present in the sinusoids (Fig.5. 2). In the vitamin C-treated group animals the livers showed normal morphological appearance similar to that of the control group (Figs 5.3 and 5.4). In the nicotine-treated group animals livers, histological examination revealed marked tissue damage. There were dilatation and congestion of the central vein and blood sinusoids (Fig. 5.5). Vacuolations of the cytoplasm and cellular degeneration were detected in some hepatocytes. Some hepatocytes had deeply stained nuclei and pale cytoplasm (Figs 5.5 and 5.6). In the nicotine+vitamin $\mathrm{C}$ treatment group animals the liver damage was milder as compared to the nicotine-treated group. The blood sinusoids were mildly dilated (Fig. 5.7). Few hepatocytes had deeply stained nuclei, while others had variable sizes of nuclei and nucleoli (Fig. 5.8).

III.5.1.2 Immunohistochemistry of the effect of nicotine versus nicotine and vitamin $C$ on proliferating cell nuclear antigen (PCNA) expression in liver tissues of rats:

We assessed the proliferation activity (regeneration) of the liver tissues by immunohistochemical staining using PCNA antibodies. In the control and vitamin C-treated groups' rat livers of the present study, there was no visible expression or nuclear reaction of PCNA (Figs 5.9 and 5.10). Nicotine administration increased the intensity of PCNA immunoreactivity in the liver cells (Fig. 5.11) as compared to control (C) 
(Fig.5. 9), and vitamin C-treated (VC) groups (Fig. 5.10). To verify the specificity of PCNA primary antibody and the immunohistochemistry protocol, when the experiment was done without using primary antibody at all the result was no brown color for PCNA immunostaining (Fig. 5.12). Vitamin C coadministration with nicotine further increased the intensity of PCNA immunoreactivity in the nuclei of liver cells as indicated by dark brown color (Fig. 5.13) in comparison with other groups.

\section{III.5.2 Transmission electron microscopy}

Examination of the control liver showed hepatocytes with rounded nuclei, many mitochondria, free ribosomes and rough endoplasmic reticulum were crowded within the cytoplasm (Fig. 5.14). Glycogen granules were also seen in the cytoplasm. In the vitamin C-treated group animals the liver was of normal morphological appearance similar to the control group (Fig. 5.15). In nicotine-treated group rat livers, the hepatocyte cytoplasm was vacuolated with destruction of mitochondria and other organelles. Lipofuscin granules, peroxisome, and lysosome were present in the cytoplasm. Also there were few numbers of free ribosomes and rough endoplasmic reticulum (Fig. 5.16). In the nicotine+vitamin $\mathrm{C}$ treatment group animals the liver damage was milder as compared to the nicotine-treated group. Numerous mitochondria and few vacuolations were seen in the cytoplasm (Fig. 5.17).

\section{III.6 Histological analysis of the kidney tissues: \\ III.6.1 Light microscopy \\ III.6.1.1 Semithin sections}

In the control group rat kidneys of the present study showed normal histological architecture. The renal cortex was formed of renal corpuscles (glomerular tuft of capillaries surrounded by Bowman's capsule) and proximal and distal convoluted tubules (Figs 6.1 and 6.2). The proximal convoluted tubules were lined by a cuboidal epithelium with basally located and spherical nuclei and prominent brush border at the apical surface (Fig. 6.2). The distal convoluted tubules were lined by cuboidal epithelial cells that lacked a brush border. The nuclei were spherical and apically located with pale cytoplasm compared with proximal convoluted tubules (Figs 6.1 and 6.2). In the vitamin C-treated group animals the kidneys showed normal morphological appearance similar to that of the control group (Figs 6.3 and 6.4). In nicotine-treated group rat kidneys, histological examination revealed marked tissue damage. The proximal and distal convoluted tubules showed partial destruction of the brush border of the proximal convoluted tubules and desquamated cells were observed inside their lumens (Figs 6.5and 6.6). Apparent thickening of the basement membrane of the distal convoluted tubules was also found. Small pyknotic nuclei and collapsed necrotic glomerulus were present. There were irregular shapes of the nuclei of some tubular cells (Fig. 6.6). Vitamin C supplementation with nicotine treatment markedly decreased the degree of injury and dilation of both PCT and DCT. Many parts of proximal convoluted tubules showed preserved brush border (figs.6.7 and 6.8).

\section{III.6.1.2 Immunohistochemistry of the Effect of nicotine versus nicotine and vitamin $\mathrm{C}$ on proliferating cell nuclear antigen (PCNA) expression in kidney tissues of rats:}

We assessed the proliferation activity (regeneration) of the kidney tissues by immunohistochemical staining via PCNA antibodies. In both of the control and vitamin C-treated groups' rat kidneys of the present study, there was no visible expression or very faint nuclear reaction of PCNA (Figs 6.9 and 6.10). Nicotine administration increased the number of PCNA-positive kidney cells as compared to other groups (Fig. 6.11). When no primary antibody was applied there was no brown color for PCNA immunostaining in the nuclei of the renal cells (Fig. 6.12). Vitamin $\mathrm{C}$ coadministration with nicotine further increased the intensity of PCNA immunoreactivity in the kidney cells as indicated by brown color in the nuclei of PCNA-positive cells (Fig. 6.13) as compared to other groups.

\section{Discussion}

Nicotine is mainly metabolized in the liver and excreted by the kidney [20]. The present study revealed that nicotine exposure for three weeks in a dose of $5 \mathrm{mg} / \mathrm{kg}$ i.p. caused significant reduction in the total body weight, relative liver and kidney weights. The reduction in liver weight is supported by a previous study showing decreased liver weight in nicotine treated rats [21]. The reduction in body weight is supported by previous studies that reported lower body weight among smokers compared to non-smokers and weight gain in most subjects who quit smoking [22] [23] [24]. Gonseth and his colleagues suggested a hormonal mechanism related to disturbed dynamics of leptin secretion after smoking cessation [25]. We found that co-exposure to nicotine and vitamin $\mathrm{C}$ failed to correct the nicotine-induced decrease in total body weight. This is supported by several studies reporting that vitamin $\mathrm{C}$ supplementation is an effective method of weight loss. According to researchers from Arizona State University, individuals having sufficient amounts of vitamin C in their body burn $30 \%$ additional amount of fat during moderately severe exercise [26]. The correlation between nonsteroidal 
vitamins such as vitamin $\mathrm{E}$ or $\mathrm{C}$ and leptin secretion in modulating body weight is previously reported [27] [28]. Taken together, we suggest an additive interaction of both nicotine and vitamin $\mathrm{C}$ in decreasing body weight through modulating leptin secretion. This particular point needs further study.

This work also demonstrated that nicotine treatment caused significant elevation of liver enzymes; ALT, AST, and ALP indicating impaired liver function. In line with us, Fahim and his group reported rise in both hepatic ALT and AST levels following I.P. nicotine injection $(1 \mathrm{mg} / \mathrm{Kg})$ for 3 weeks in mice [29]. Another study observed overexpression of ALP level and other genes involved in osteoblast maturation and differentiation in osteoblasts in response to subtoxic nicotine administration in humans [30]. Histological examination of the liver showed marked centrilobular congestion, dilatation of central vein and blood sinusoids, cellular degeneration with loss of trabecular arrangement in the nicotine-treated group. In addition, vacuoles appeared in many hepatocytes, indicating possible fatty changes. The ultrastructural examination of the liver revealed, the nucleus of the hepatocyte had clumped heterochromatin with an irregular thick nuclear membrane, rarified cytoplasm, cytotoxic and degenerative changes in hepatic cells. Actually the damaging effect of smoking on liver diseases has been previously reported [30]. In addition, we found severe destruction of the mitochondria, presence of lipofuscin granules and peroxisome, and decreased number of cytoplasmic organelles in hepatocytes from nicotine-treated rats only. Commensurate with the present results, some investigators described that nicotine has strong affinity to mitochondria [31]. They hypothesized that altered cellular energy metabolism is involved in the pathogenesis of nicotine toxicity. It was reported that the major source of lipofuscin granules is incomplete lysosomal degradation of damaged organelles as was shown in a model of aging [32]. Lipofuscin sensitizes the cells to oxidative stress, as the accumulation of defective mitochondria produces more reactive oxygen species, which causes additional damage [33] [34]. Nevertheless, the peroxisomes are major sites of oxygen utilization and contain oxidative enzymes as urate oxidase for detoxification [34]. The enzyme oxidase can create hydrogen peroxide as a byproduct of its enzymatic reactions within the peroxisome. Hydrogen peroxide can then be converted to water by enzymes like catalase and peroxidase present in the peroxisome [34]. Coadministration of vitamin $\mathrm{C}$ and nicotine significantly decreased liver enzymes ALT, AST, and ALP compared to nicotine treated group. This result is supported by the work of $\mathrm{Su}$ and his colleague who reported a hepatoprotective effect of vitamin $\mathrm{C}$ against carbon tetrachloride-induced liver damage and elevation of liver enzymes [35]. Moreover, this study showed that vitamin C supplementation decreased the degree of hepatocyte injury and vacuolation of its cytoplasm. In hand with our results, earlier studies reported that both vitamin $\mathrm{E}$ and vitamin $\mathrm{C}$ were effective in improving fibrosis scores in patients with nonalcoholic steatohepatitis [36] [37].

In addition, our study showed that nicotine caused dilation and marked destruction of cells lining the proximal and distal convoluted tubules of the rat kidney. Presence of collapsed fibrotic renal glomeruli may be secondary to increased collagen fiber formation or glomerulosclerosis caused by several toxic agents [38]. Moreover, we found that some cells of the proximal and distal convoluted tubules of the rat kidney of nicotinetreated group had nuclei of irregular shapes. It has been reported that irregular nuclear shape indicates mitotic instability that might be associated with genetic aberrations [39] [40]. Previous researchers found that abnormal nuclear shape is associated with premature and normal aging, as well as cancer [41] [42] [43]. The changes observed in the kidney are greatly improved by the use of vitamin C. Consistent with our results; one study revealed that vitamin $\mathrm{C}$ antagonized nicotine-induced kidney damage through reduction of fibronectin accumulation in proximal tubules of the kidney [44].

Moreover, our results showed elevation of oxidative stress marker; malondialdehyde (MDA) however, it doesn't significantly change the level of antioxidant marker; glutathione in both liver and kidney tissues. This result is supported by previous studies reporting that tobacco caused hepatic damage both in vitro and in vivo due to oxidative stress associated with lipid peroxidation [45] [46] through induction of cytochrome P-450 [47]. In agreement with us, another study reported elevation of MDA in liver tissues-induced by nicotine and aggravated by ethanol [21]. Our results also revealed that co-exposure to nicotine and vitamin $\mathrm{C}$ caused significant reduction in the levels of MDA. Vitamin $\mathrm{C}$ also caused a significant elevation of glutathione compared to nicotine treated group as well as control. This result is supported by in vivo study demonstrating that vitamin C prevents oxidative damage caused cigarette smoking [37].

In normal conditions the hepatocytes remain in quiescent state (phase $\mathrm{G} 0$ of the cell cycle), but retain the ability to reinitiate the cell cycle with occasion of tissue damage, tissue loss or exogenous stimulus (growth factors, mitogens) [48] [49] [50]. Thus, in normal conditions mitosis is observed only in one out of 20,000 hepatocytes [51]. Immunohistochemical demonstration of proliferating cell nuclear antigen (PCNA) showed that nicotine causes significant elevation in the number of PCNA positive hepatocytes. This result is supported by the work of Wiśniewska and his group who showed that nicotine coadministration with alcohol significantly increasing PCNA expression in pancreatic and hepatic rat cells [52]. PCNA is an auxiliary protein of DNA polymerase delta and is involved in a wide range of functions in the nucleus such as control of DNA replication, cell-cycle progression, transcription as well as DNA damage repair [53] [54]. The concentration of the PCNA 
protein in the nucleus increases in the final stage of G1 phase of the cell cycle and reaches maximum value in $\mathrm{S}$ phase. Total absence of this protein could be observed in G0 phase [55] [56].

We found that vitamin $\mathrm{C}$ coadministrattion enhances the effect of nicotine in the liver and kidney through increasing PCNA expression significantly in both tissues. In agreement with our results Gürgen and his colleagues suggested that ascorbic acid through increasing PCNA expression reduced the cyclophosphamideinduced damage of rat ovarian tissue [57]. Another study showed that coadministration of ascorbic acid and kojic acid increased the number of liver cells positive for PCNA and reduced the number of TUNEL-positive cells probably through its antioxidant activity [58]. Taken together, the results of present work provides a further evidence for the liability toward the occurrence of liver and kidney damage in rather healthy individuals with daily exposure to nicotine. Moreover, it demonstrated the protective effect of vitamin $\mathrm{C}$ against the oxidative damage induced by nicotine on liver and kidney tissues. Finally, we encourage smokers to consume high vitamin $\mathrm{C}$ supplement to protect their liver and kidney from oxidative damage induced by nicotine.

\section{Conclusion}

The aim of this study was to evaluate the detrimental effects of administration of nicotine alone for three weeks or combined with vitamin $\mathrm{C}$ on the antioxidant defense status, functional, histopathological changes, and proliferating capacity in liver and kidney tissues of young adult male rats. The major findings of this study is that i.p. injection of nicotine at a dose $5 \mathrm{mg} / \mathrm{Kg}$ body weight for 3 weeks is associated with reduction in liver, kidney weight as well as total body weight, elevated liver enzymes, hepatic PCNA expression, and increased oxidative stress in rat liver and kidney tissues. All these disturbances are considered as indicators for occurrence and progression of hepatic and kidney disease that is proved by histopathology. Prophylactic vitamin C supplementation at a dose of $0.3 \mathrm{~g} / \mathrm{Kg}$ i.p. 3 days prior, with nicotine injection and 2 day thereafter significantly reduced malondialdehyde, liver enzymes and elevated glutathione level in liver and kidney tissue. Histopathological examination of the liver and kidney tissues revealed marked tissue damage in nicotine-treated group compared to the control that is greatly reduced by vitamin $\mathrm{C}$ supplementation. Vitamin $\mathrm{C}$ coadministration significantly increased the proliferating capacity of hepatic and renal tissue as indicated by increasing the number of PCNA positive cells. We suggest that vitamin $\mathrm{C}$ has a promising pharmacological prophylactic role against liver and kidney damage that is induced by nicotine.

\section{Conflict Of Interest}

No conflict of interest.

\section{References}

[1] G Zhang, K.A. Kernan, A. Thomas, S. Collins, Y. Song, L. Li, W. Zhu, R.C. Leboeuf, and A.A. Eddy, A novel signaling pathway: fibroblast nicotinic receptor alpha1 binds urokinase and promotes renal fibrosis. J. Biol. Chem. 284, 2009, $29050-29064$.

[2] NL Benowitz, H. Porchet, L. Sheiner, and P. Jacob, Nicotine absorption and cardiovascular effects with smokeless tobacco use: Comparison with cigarettes and nicotine gum. Clinical Pharmacology and Therapeutics 4, 1988, 23-28.

[3] H. Schievelbein and D.J.K. Balfour, Nicotine and the Tobacco Smoking Habit. Pergamon Press, Oxford, $1984,1-15$.

[4] SL Wang, X.Y. He, and J.Y. Hong, Human cytochrome p450 2s1: lack of activity in the metabolic activation of several cigarette smoke carcinogens and in the metabolism of nicotine, Drug Metab. Dispos., 33, 2005, 336- 340.

[5] C Kalpana and V.P. Menon, Protective effect of curcumin on circulatory lipid peroxidation and antioxidant status during nicotineinduced toxicity. ToxicolMech Methods. 14, 2004, 339-343.

[6] SK Mahapatra, S. P. Chakraborty, S. Das, and S. Roy, Methanol extract of Ocimum gratissimum protects murine peritoneal macrophages from nicotine toxicity by decreasing free radical generation, lipid and protein damage and enhances antioxidant protection, Oxidative Medicine and Cellular Longevity 2:4, 2009, 222-230.

[7] S Muthukumaran, A.R. Sdheer, V.P. Menon, N. Nalini, Protective effect of quercetin on nicotine induced prooxidant and antioxidant imbalance and DNA. Toxicology 243, 2008, 207-215.

[8] J Du, J.J. Cullena, and G.R. Buettnera, Ascorbic acid: Chemistry, biology and the treatment of cancer. Biochim Biophys Acta. 1826(2), 2012, 443-457.

[9] J Duconge, J.R. Miranda-Massari, M.J. Gonzalez, J.A. Jackson, W. Warnock, and N.H. Riordan, Pharmacokinetics of vitamin C: insights into the oral and intravenous administration of ascorbate. P R Health Sci J. 27(1), 2008, 7-19.

[10] GL Moldovan, B. Pfander, and S. Jentsch, PCNA, the maestro of the replication fork. Cell May 18, 129 (4), $2007,665-79$.

[11] I Bruck, M. O'Donnell, The ring-type polymerase sliding clamp family. Genome Biol. 2 (1), 2001 : REVIEWS3001.

[12] V Mizrahi, R.N. Henrie, J.F. Marlier, K.A. Johnson, and S.J. Benkovic, Rate-limiting steps in the DNA polymerase I reaction pathway. Biochemistry 24 (15), 1985, 4010-4018.

[13] H Ohkawa, N. Ohishi, K. Yagi, Anal Biochem. Assay for lipid peroxides in animal tissues by thiobarbituric acid reaction. Jun;95(2), 1979, 351-8.

[14] SS Kaya, A. Mahmood, Y. Li, E.Yavuz, M. Goksel and M. Chopp, Apoptosis and expression of p53 response proteins and cyclin D1 after cortical impact in rat brain. Brain Res. 818(1), 1999, 23-33.

[15] AFSA Habeeb, Reaction of protein sulfhydryl groups with Ellman's reagent. Methods in Enzymology, Vol 25, $1972,457-464$.

[16] RAB Drury and E.A.Wallington, Carleton's histological technique (Oxford University Press. New York, USA, 1980).

[17] G Cattoretti, S. Pileri, C. Parravicini, M.H.G. Becker, S. Poggi, C. Bifulco, et al. Antigen unmasking on formalin-fixed, paraffinembedded tissue sections, J Pathol; 171, 1993, 83-98.

[18] SM Hsu, L. Raine, and H. Fanger, Use of avidin-biotin-peroxidase complex (ABC) in immunoperoxidase techniques: a comparison between ABC and unlabeled antibody (PAP) procedures. J Histochem Cytochem; 29, 1981, 577-580.

[19] J.J. Bozzola, L.D.Russell, Electron microscopy: principles and techniques for biologists. (Boston: Jones \& Bartlett Pub: 1992). 
[20] J.H. Jaffe, Drug addiction and drug abuse, in A.G. Gilman, T.W. Rall, A.S. Niess, P. Taylor, (Eds.), Goodman and Gillman's the Pharmacological Basis of Therapeutics, 8 (Pergamon, New York. 1990) 522-573.

[21] H Dhouib, M. Jallouli, M. Draief, S. El-Fazaa1, S. Bouraoui, The effect of nicotine and its interaction with ethanol on biochemical parameters, oxidative damage and histological changes in the rat's liver, IOSR Journal Of Environmental Science, Toxicology And Food Technology (IOSR-JESTFT) e-ISSN: 2319-2402,p- ISSN: 2319-2399. Volume 8, Issue 1 Ver. V, Feb, 2014, PP 72-82.

[22] C Filozof , M.C. Fernández Pinilla, and A. Fernández-Cruz, Smoking cessation and weight gain. Obes Rev Off J Int Assoc Study Obes. 5, 2004, 95-103.

[23] JA Fulkerson and S.A. French, Cigarette smoking for weight loss or control among adolescents: gender and racial/ethnic differences. J Adolesc Health Off Publ Soc Adolesc Med. 32, 2003, 306-313.

[24] KA Meyer, L.H. Kushi, D.R. Jacobs, and A.R. Folsom, Dietary Fat and Incidence of Type 2 Diabetes in Older Iowa Women. Diabetes Care, 24, 2001, 1528-1535.

[25] S Gonseth, I. Locatelli, R. Bize, S. Nusslé, C. Clair, F. Pralong, and J. Cornuz, Leptin and smoking cessation: secondary analyses of a randomized controlled trial assessing physical activity as an aid for smoking cessation. BMC Public Health. 3;14(1), 2014, 911.

[26] CS Johnston, Strategies for healthy weight loss: from vitamin C to the glycemic response. J Am Coll Nutr. Jun;24(3), 2005,158-65.

[27] C Menendez, M. Lage, R. Peino, R. Baldelli, P. Concheiro, C. Diéguez and F.F. Casanueva, Retinoic acid and vitamin D3 powerfully inhibit in vitro leptin secretion by human adipose tissue. Journal of Endocrinology 170, 2001, 425-431.

[28] OP García, D. Ronquillo, M.d.C. Caamaño, M. Camacho, K.Z. Long, and J.L. Rosado, Zinc, vitamin A, and vitamin C status are associated with leptin concentrations and obesity in Mexican women: results from a cross-sectional study. Nutrition \& Metabolism, 2012, 9:59.

[29] MA Fahim, A. Nemmar, S. Al-Salam, S. Dhanasekaran, M. Shafiullah, J. Yasin, M.Y. Hassan, Thromboembolic injury and systemic toxicity induced by nicotine in mice. Gen Physiol Biophys. 33(3), 2014, 345-55.

[30] L Marinucci, M. Bodo, S. Balloni, P. Locci, T. Baroni, Sub-toxic nicotine concentrations affect extracellular matrix and growth factor signaling gene expressions in human osteoblasts. J Cell Physiol. Dec;229(12), 2014, 2038-48.

[31] H. Takashi, Y. Masashi, S. Tadahito, K. Mieko and T. Akira, Intraportal nicotine infusion in rats decreases hepatic blood flow through endothelin-1 and both endothelin A and endothelin B receptors. Toxicology and Applied Pharmacology, 196, 2003, 1-10.

[32] A Cormier, C. Morin, R. Zini, J.P. Tillement, and G.Lagrue, In vitro effects of nicotine on mitochondrial respiration and superoxide anion generation. Brain Res 900, 2001, 72-79.

[33] K Kitani, Aging and the liver: functional aspects. Arch Gerontol Geriatr. 19(2) 1994, 145-58.

[32] A Terman, B. Gustafsson, U.T. Brunk, Mitochondrial damage and intralysosomal degradation in cellular aging. Mol Aspects Med 27, 2006, 471-482.

[34] B. Alberts, A. Johnson, J. Lewis, M. Raff, K. Roberts, et al., Molecular biology of the cel. 4th ed. P. 1759-1763, (New York: Garland Science. 2002).

[35] M Su, H. Chen, C. Wei, N. Chen, W. Wu, Potential protection of vitamin C against liver-lesioned mice. Int Immunopharmacol. Oct;22(2), 2014, 492-7.

[36] K. Panda, R. Chattopadhyay, D.J. Chattopadhyay, et al. Vitamin C prevents cigarette smoke-induced oxidative damage in vivo. Free Radic Biol Med 29, 2000, 115-24.

[37] SA Harrison, S. Torgerson, P. Hayashi, J. Ward, and S. Schenker, Vitamin E and vitamin C treatment improves fibrosis in patients with nonalcoholic steatohepatitis. The American Journal of Gastroenterology 98, 2003, 2485-2490.

[38] FMM Lai, C.C. Szeto, P.C.L. Choi, K.K.L. Ho, N.L.S. Tang, K.M. Chow, et al. Isolate diffuse thickening of glomerular capillary basement membrane: a renal lesion in prediabetes? Mod Pathol, 17, 2004, 1506-1512.

[39] K Erhardt, C. Silfverswärd, G. Auer, Nuclear DNA content and nuclear atypia. Relation to survival in patients with breast adenocarcinoma and serous ovarian tumors. Anticancer Res 9, 1989, 1325-1330.

[40] D Gisselsson, J. Björk, M. Höglund, F. Mertens, P. Dal Cin, M. Ákerman, and N. Mandahl, Abnormal nuclear shape in solid tumors reflects mitotic instability. Am J Pathol 158(1), 2001,199-206.

[41] D Zink, A.H. Fischer, and J.A.Nickerson, Nuclear structure in cancer cells. Nat. Rev. Cancer 4, 2004, 677-687.

[42] E Haithcock, Y. Dayani, E. Neufeld, A.J. Zahand, N. Feinstein, A. Mattout, Y. Gruenbaum, J. Liu, Age-related changes of nuclear architecture in Caenorhabditis elegans. Proc. Natl. Acad. Sci. USA 102, 2005, 16690-16695.

[43] P Scaffidi, T. Misteli, Lamin A-dependent nuclear defects in human aging. Science 312, 2006, 1059-1063.

[44] H Pahang, M. R. Nikravesh, M. Jalali, A. E. Bideskan, P. Zargari, and A. S. Nabavi, Fibronectin regulation by vitamin C treatment in kidneys of nicotinic mice offspring, Iranian Red Crescent Medical Journal, July; 16(7), 2014, e17056.

[45] M Bagchi, D. Bagchi, EA. Hassoun, et al. Smokeless tobacco induced increases in hepatic lipid peroxidation, DNA damage and excretion of urinary lipid metabolites. Int J Exp Pathol 75, 1994, 197-202.

[46] AR Gogo, C.H. Cho, S.T. Yuen, et al, The cytotoxic effect of nicotine on the liver and its modulation of hepatotoxicity induced by carbon tetrachloride in rats. Eur J Gastroenterol Hepatol 5, 1993, 859-65.

[47] ZZ Guan, W.F. Yu, A. Nordberg, Dual effects of nicotine on oxidative stress and neuroprotection in PC12 cells. Neurochem. Int. $43,2003,243-249$.

[48] D.O. Morgan, The cell cycle: Principles of control, in D.O. Morgan (Ed.), The cell cycle (London: New Science Press, 2007) 1-9.

[49] A Chauhan, S. Lorenzen, H. Herzel, and S. Bernard, Regulation of mammalian cell cycle progression in the regenerating liver. J Theor Biol 283, 2011, 103-12.

[50] JA Cienfuegos, F. Rotellar, J. Baixauli, F. Martínez-Regueira, F. Pardo, J.L. Hernández-Lizoáin, Liver regeneration - The best kept secret. A model of tissue injury response. Rev Esp Enferm Dig (Madrid) 106(3), 2014, 171-194.

[51] N Fausto, Liver regeneration. J Hepatol. 32(1 Suppl), 2000, 19-31.

[52] E. Wiśniewska, A. Dylik, M. Kulza, E. Florek, W. Piekoszewski, M. Seńczuk-Przybyłowska, and A. Marszałek, Exposure to ethanol and tobacco smoke in relation to level of PCNA antigen expression in pancreatic and hepatic rat cells. Pharmacol Rep. ;65(4), 2013, 914-26.

[53] Z Kelman, PCNA: structure, functions and interactions. Oncogen, 14, 1997, 629-640.

[54] M.Y. Lee, S. Zhang, S.H. Lin, J. Chea, X. Wang, C. Leroy, and A. Wong, Regulation of human DNA polymerase delta in the cellular responses to DNA damage. Environ Mol Mutagen 53, 2012, 683-698.

[55] M Selzner and P.A. Clavien, Failure of regeneration of the steatotic rat liver: disruption at two different levels in the regeneration pathway. Hepatology 31, 2000, 35-42.

[56] N Selzner, M. Selzner, Y. Tian, Z. Kadry, and P.A. Clavien, Cold ischemia decreases liver regeneration after partial liver transplantation in the rat: a TNF-a/IL-6-dependent mechanism. Hepatology 36, 2002, 812-818.

[57] SG Gürgen, D. Erdoğan, C. Elmas, G.T. Kaplanoğlu, and C. Ozer, Chemoprotective effect of ascorbic acid, $\alpha$-tocopherol, and selenium on cyclophosphamide-induced toxicity in the rat ovarium. Nutrition. May;29(5), 2013, 777-84. 


\section{Figures}
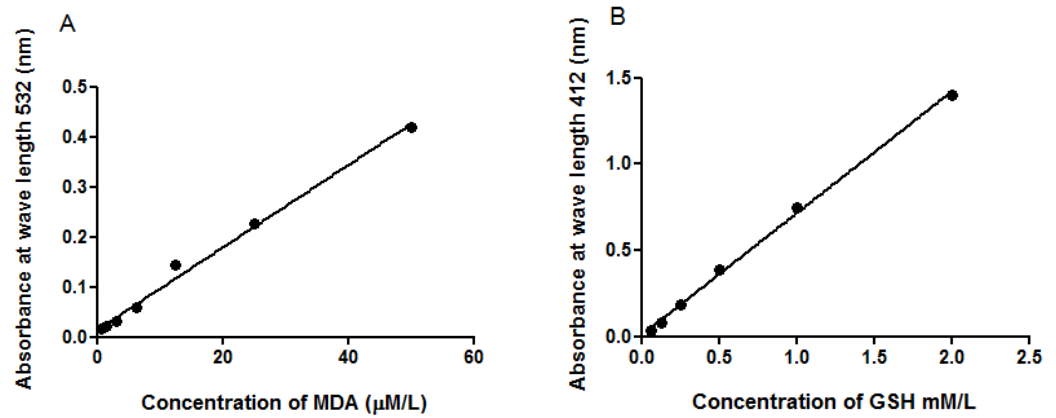

Figure 1: (A) Standard curve of malondiadehyde (MDA) and (B) glutathione (GSH). Absorbance is read at 532nM for MDA and 412nM for GSH using UV-Visible spectrophotometer Pharmacia LKB- Ultraspec Plus. (mM/ $\mathrm{L}=$ millimole/Liter, $\mu \mathrm{M} / \mathrm{L}=$ micromole/ liter, $\mathrm{nm}=$ nanometer wavelength).
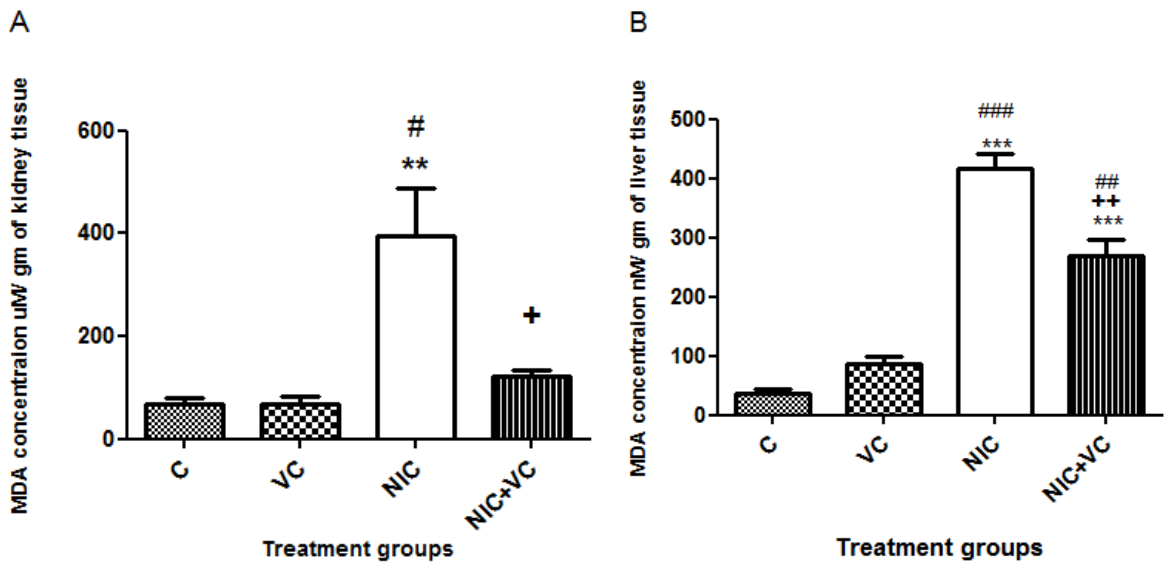

Figure 2: Effect of nicotine versus nicotine and vitamin $\mathrm{C}$ on Malondialdehyde (MDA) concentration in renal tissues (A) and hepatic tissues (B) of rats: $\mathrm{C}$; saline treated-control; $\mathrm{VC}=$ vitamin $\mathrm{C}$-treated control, NIC $=$ nicotine treated group; $\mathrm{NIC}+\mathrm{VC}=$ nicotine and vitamin $\mathrm{C}$ treated group. All values are expressed as mean $+/-$ SEM, One Way ANOVA with Bonferroni's Multiple Comparison Test was used. (*) compared to C group, (\#) compared to VC group, (+) compared to NIC+VC group. $(\mathrm{n}=6)$.

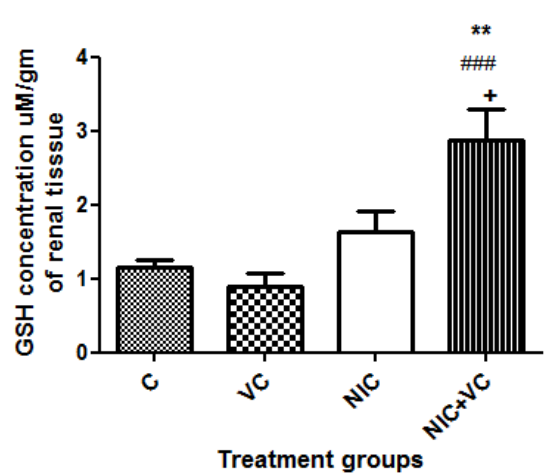

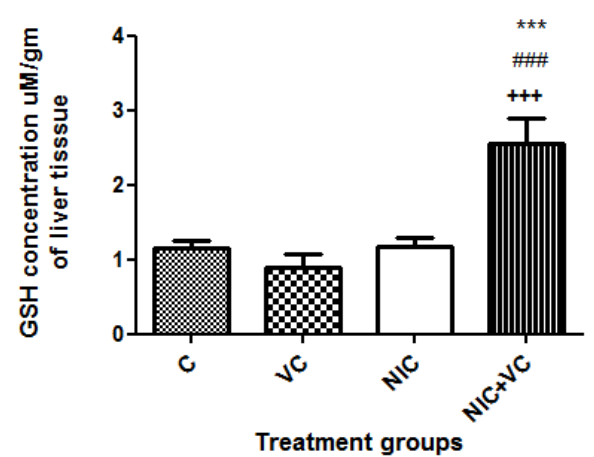

Figure 3: Effect of nicotine versus nicotine and vitamin $\mathrm{C}$ on Glutathione (GSH) concentration in renal tissues

(A) and hepatic tissues (B) of rats: $\mathrm{C}$; saline treated-control; $\mathrm{VC}=$ vitamin $\mathrm{C}$-treated control, NIC $=$ nicotine treated group; $\mathrm{NIC}+\mathrm{VC}=$ nicotine and vitamin $\mathrm{C}$ treated group. All values are expressed as mean $+/-\mathrm{SEM}$, One Way ANOVA with Bonferroni's Multiple Comparison Test was used. (*) compared to C group, (\#) compared to VC group, (+) compared to NIC+VC group $(n=6)$. 
A

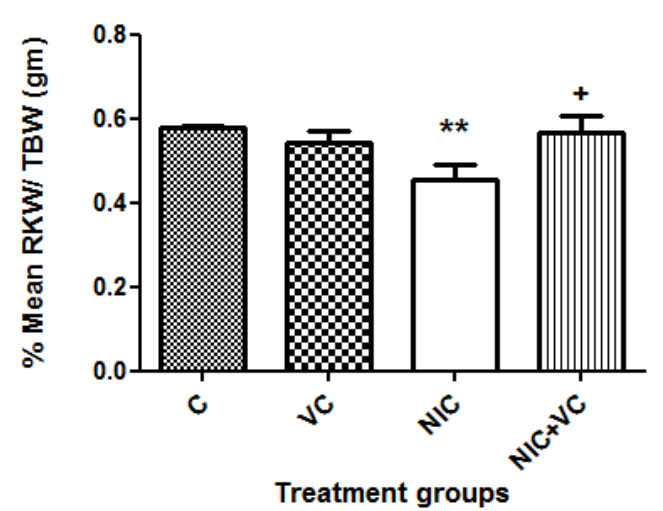

C

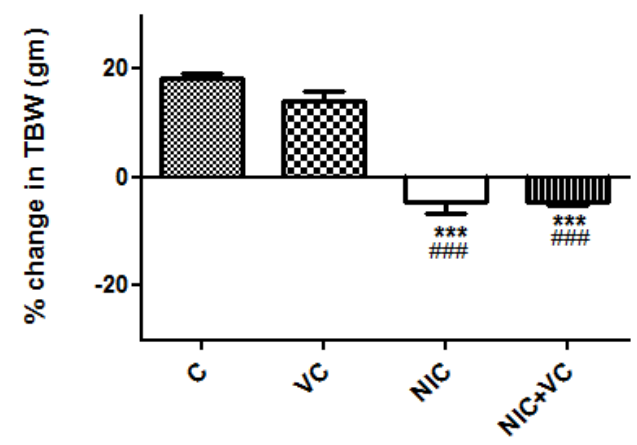

Treatment groups

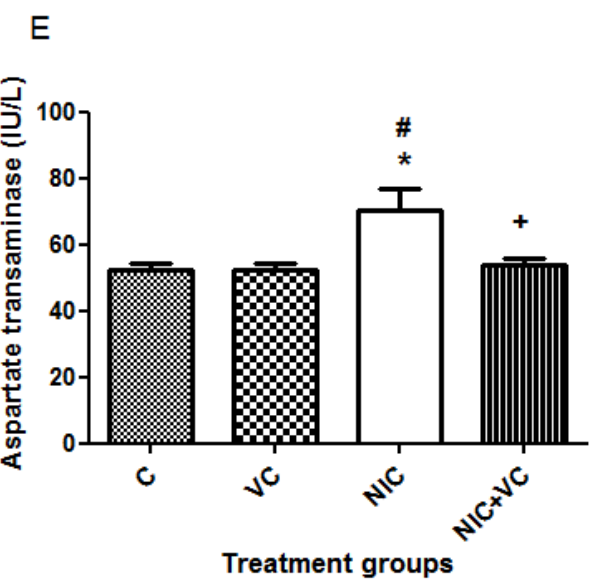

B

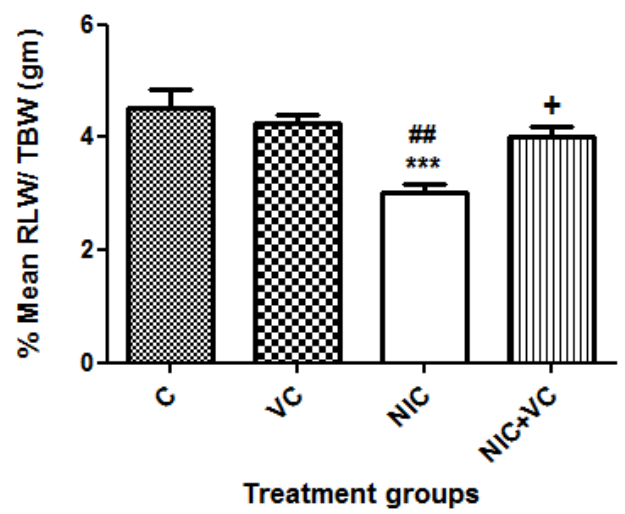

$\mathrm{D}$

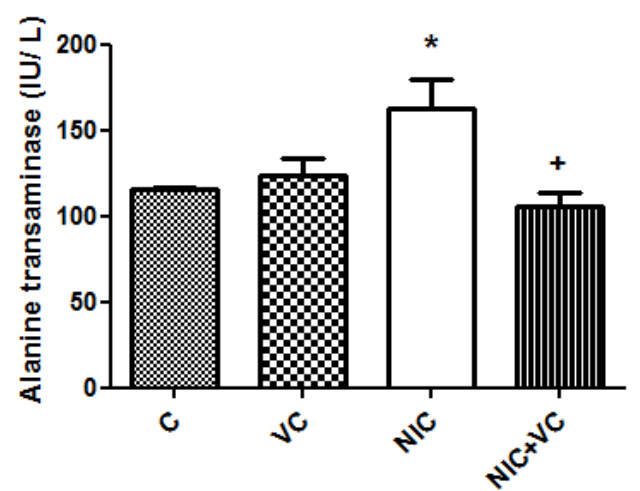

Treatment groups

$\mathrm{F}$

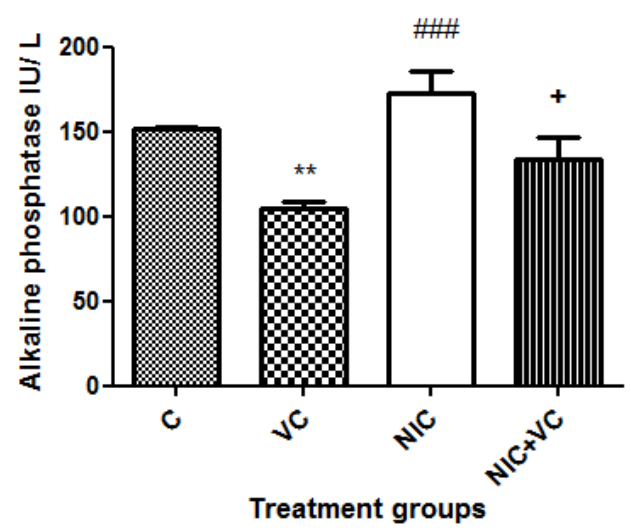

Figure 4: Effect of nicotine versus nicotine and vitamin C on A: relative kidney weight (RKW), B: relative liver weight (RLW) and, C: Total body weight of rats (TBW), D: alanine transaminase (ALT), E: Aspartate transaminase (AST), F: Alkaline phosphatase (ALP) level in liver homogenate. $\mathrm{C}=$ saline treatedcontrol; $\mathrm{VC}=$ vitamin $\mathrm{C}$ treated control, $\mathrm{NIC}=$ nicotine treated group; $\mathrm{NIC}+\mathrm{VC}=$ nicotine and vitamin $\mathrm{C}$ treated group. All values are expressed as mean +/-SEM., One Way ANOVA with Bonferroni's Multiple Comparison Test was used. $(*)$ compared to $\mathrm{C}$ group, (\#) compared to VC group, (+) compared to NIC+VC group. $(\mathrm{n}=8)$. 


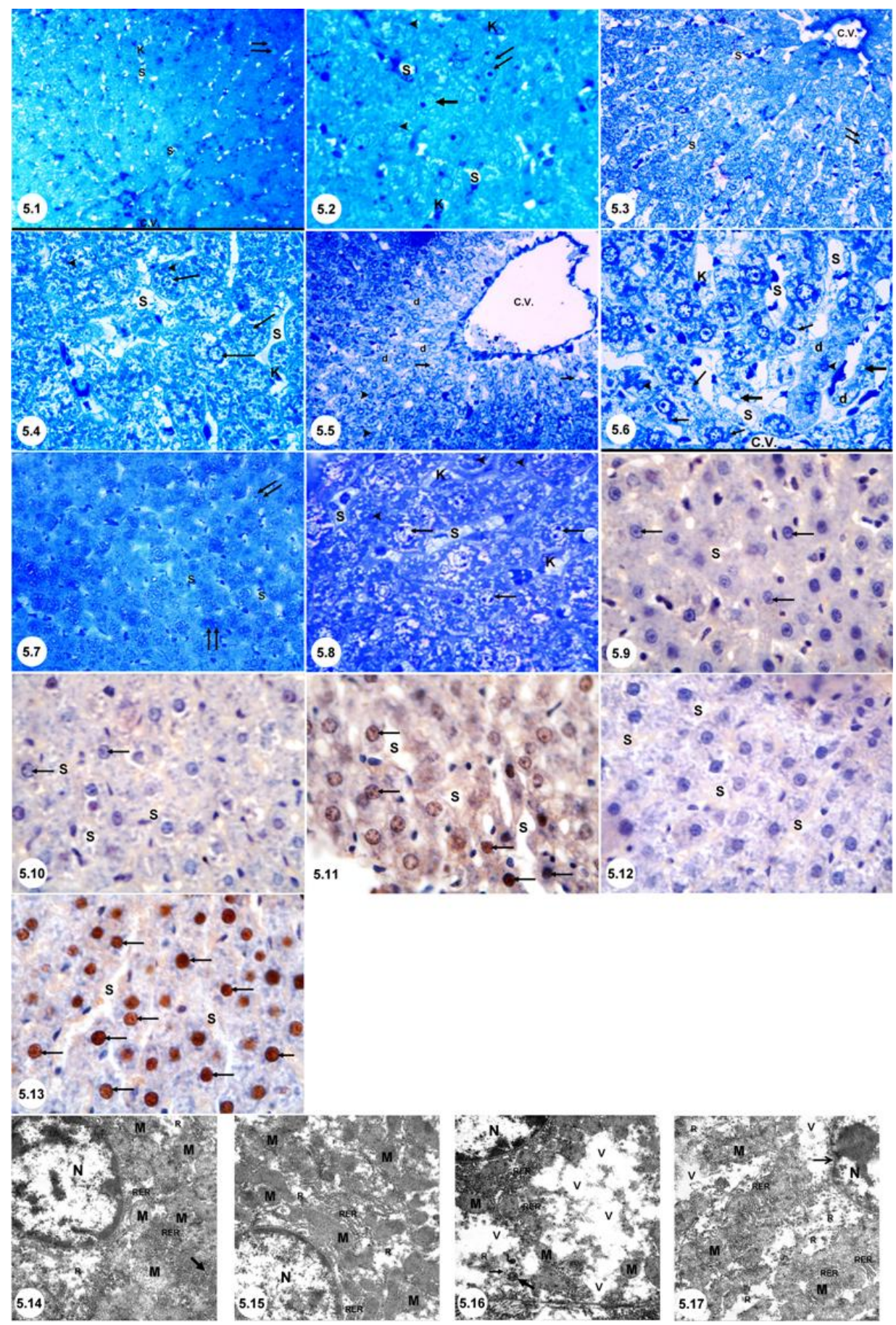

Figure 5.1. A photomicrograph of a semithin section of the liver of control rat group showing normal appearance of radiating cords of hepatocytes from the central vein (C.V.) and narrow blood sinusoids (S) in between. Some hepatocytes are binucleated (double arrows). Note the presence of Kupffer cells (K) in the sinusoids. Toluidine blue, $\times 400$.

Figure 5.2. A photomicrograph of a semithin section of the liver of control rat group showing hepatocytes with basophilic bodies (arrow heads) and vesicular nuclei (arrows). The cords of hepatocytes separated by blood sinusoids (S). Some hepatocytes are binucleated (double arrows). Note the presence of Kupffer cells (K) in the sinusoids. Toluidine blue, $\times 1000$

Figure 5.3. A photomicrograph of a semithin section of the liver of vitamin C- treated rat group showing the central vein (C.V.) with radiating cords of hepatocytes and narrow sinusoids in between. Some hepatocytes are binucleated (double arrows). Toluidine blue, $\times 400$.

Figure 5.4. A photomicrograph of a semithin section of a liver of vitamin C-treated rat group showing hepatocytes with basophilic bodies (arrow heads) and vesicular nuclei (arrows). The cords of hepatocytes 
separated by blood sinusoids (S). Note the presence of Kupffer cells (K) in the sinusoids. Toluidine blue, $x$ 1000 .

Figure 5.5. A photomicrograph of a section of the liver from nicotine-treated rat group showing marked congestion of the central vein (C.V.), and some hepatocytes with deeply stained nuclei (arrowheads), and areas of cellular degeneration (d). Some hepatocytes have vacuolated cytoplasm (arrows). Toluidine blue, $\times 400$.

Figure 5.6. A photomicrograph of a semithin section of the liver from nicotine-treated rat group showing the central vein (C.V.) and hepatocytes with apparent reduction of basophilic cytoplasmic granules (thin arrows), and dilatation of blood sinusoids (S). Some hepatocytes have shrunken pyknotic nuclei (arrowheads), and areas of cellular degeneration (d). Some hepatocytes have vacuolated cytoplasm (thick arrows), and Kupffer cells (K) present in the sinusoids. Toluidine blue, $\times 1000$.

Figure 5.7. A photomicrograph of a semithin section of the liver from nicotine+vitamin C-treated rat group showing cords of hepatocytes and blood sinusoids $(S)$ in between. Some hepatocytes are binucleated (double arrows). Toluidine blue, $\times 400$.

Figure 5.8. A photomicrograph of a semithin section of the liver from nicotine+vitamin C-treated rat group showing cords of hepatocytes and blood sinusoids (S) in between. The hepatocytes have variable sizes of nuclei and nucleoli. Some nuclei are pyknotic densely stained (arrowheads), while others are large with 2 or more nucleoli (arrows). Kupffer cells (K) present in the sinusoids. Toluidine blue, $\times 1000$.

Figure 5.9. A photomicrograph of a paraffin section of the liver from control rat group showing no proliferating cell nuclear antigen (PCNA) immunohistochemical localization in the nuclei of hepatocytes. The hepatocytes have vesicular basophilic nuclei (arrows) and blood sinusoids $(\mathrm{S})$ in between. PCNA immunostain counterstained with $\mathrm{H} \& \mathrm{E}, \times 1000$.

Figure 5.10. A photomicrograph of a paraffin section of the liver from vitamin $\mathrm{C}$-treated rat group showing no proliferating cell nuclear antigen (PCNA) immunohistochemical localization in the nuclei of hepatocytes. The hepatocytes have vesicular basophilic nuclei (arrows) and blood sinusoids (S) in between. PCNA immunostain counterstained with $\mathrm{H} \& \mathrm{E}, \times 1000$.

Figure 5.11. A photomicrograph of a paraffin section of the liver from nicotine-treated rat group showing positive reaction for proliferating cell nuclear antigen (PCNA) immunohistochemical localization in the nuclei of hepatocytes. The hepatocytes nuclei have brown immunostain (arrows) and blood sinusoids (S) present in between. PCNA immunostain counterstained with H\&E, $\times 1000$.

Figure 5.12. A photomicrograph of a paraffin section of the liver from nicotine-treated rat group used to test the specificity of PCNA antibodies and immunohistochemistry. When no primary antibody was applied there was no brown color for PCNA immunostain. The hepatocytes are separated by blood sinusoids (S). PCNA immunostain counterstained with H\&E, $\times 1000$.

Figure 5.13. A photomicrograph of a paraffin section of the liver from nicotine+vitamin C-treated rat group showing strong positive reaction for proliferating cell nuclear antigen (PCNA) immunohistochemical localization in the nuclei of hepatocytes. The hepatocytes nuclei have dark brown immunostain (arrows) and blood sinusoids (S) present in between. PCNA immunostain counterstained with H\&E, $\times 1000$.

Figure 5.14. Transmission electron micrograph of a portion of the liver from control group showing a hepatocyte with normal morphological appearance of nucleus (N) and heterochromatin clumps. The cytoplasm is rich in mitochondria (M), and has many rough endoplasmic reticulum cisternae (RER) and free ribosomes (R). Note the presence of glycogen granules (thick arrow). Uranyl acetate and Lead citrate, $\times 10000$.

Figure 5.15. Transmission electron micrograph of a portion of the liver from vitamin C-treated group showing a hepatocyte with normal morphological appearance of nucleus $(\mathrm{N})$. The cytoplasm contains many mitochondria (M), and has numerous rough endoplasmic reticulum cisternae (RER) and free ribosomes (R). Uranyl acetate and Lead citrate, $\times 10000$.

Figure 5.16. Transmission electron micrograph of a portion of the liver from nicotine-treated group showing a hepatocyte with clumps of heterochromatin in the nucleus $(\mathrm{N})$. The cytoplasm is vacuolated $(\mathrm{V})$ with destroyed and dispersed organelles, and apparent reduction in the number of mitochondria $(\mathrm{M})$, free ribosomes $(\mathrm{R})$ and rough endoplasmic reticulum cisternae (RER). Note the presence of damaged mitochondria, lipofuscin granules (thick arrow), peroxisome (thin arrow) and lysosomes (L). Uranyl acetate and Lead citrate, $\times 10000$.

Figure 5.17. Transmission electron micrograph of a portion of the liver from nicotine+vitamin $C$ treatment group showing a hepatocyte with nucleus $(\mathrm{N})$, that has indentation of the nuclear envelop (arrow) and prominent nucleolus. The cytoplasm shows some vacuolations $(\mathrm{V})$, and has numerous mitochondria $(\mathrm{M})$, many free ribosomes (R) and rich in rough endoplasmic reticulum cisternae (RER). Uranyl acetate and Lead citrate, $\times 10000$. 


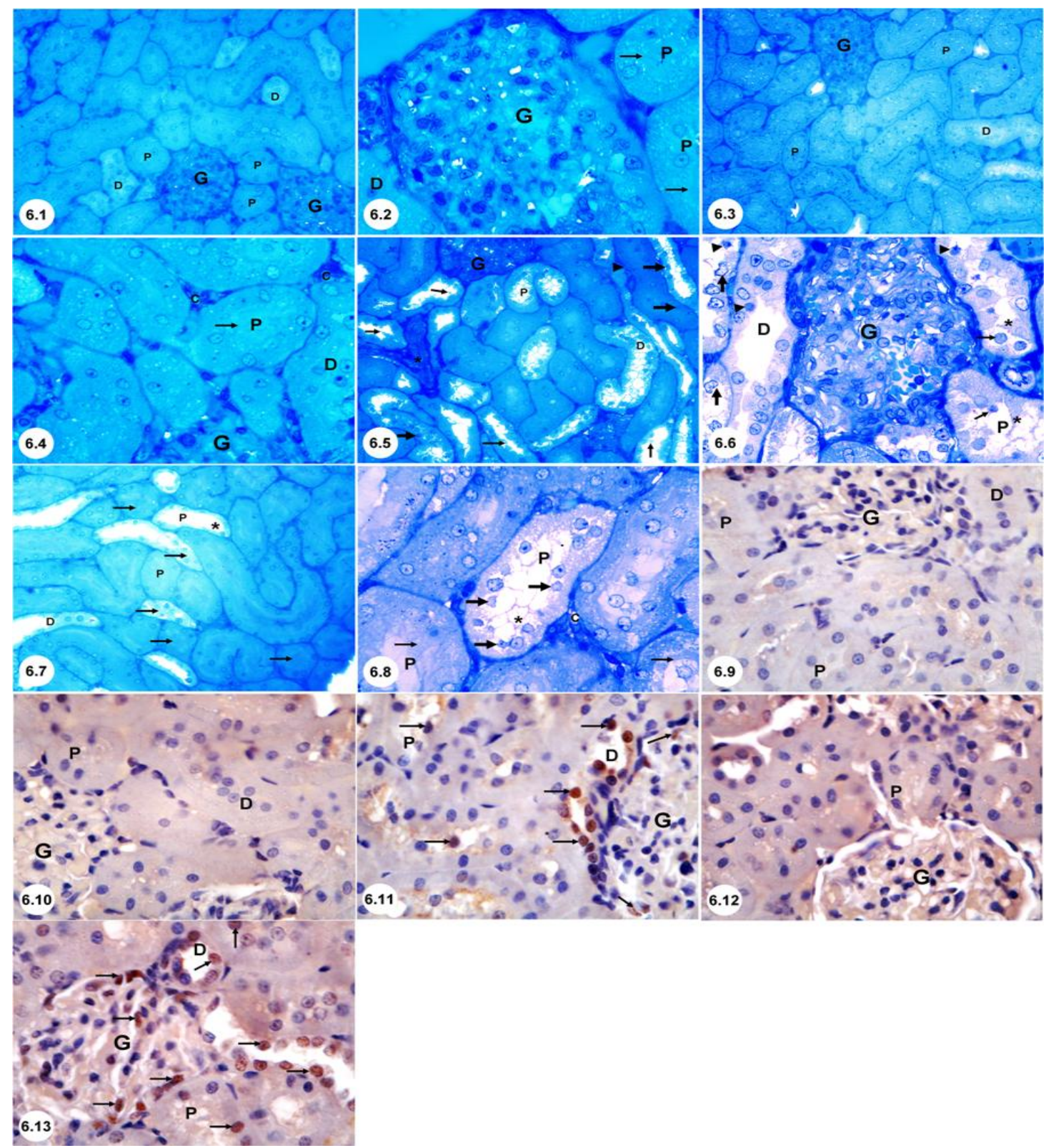

Figure 6.1. A photomicrograph of a semithin section of the renal cortex of control rat group showing a glomerular tuft of capillaries $(\mathrm{G})$, proximal convoluted tubules $(\mathrm{P})$, and distal convoluted tubules (D). Toluidine blue, $\times 400$.

Figure 6.2. A photomicrograph of a semithin section of the renal cortex of control rat group showing; glomerular tuft of capillaries $(\mathrm{G})$, parts of proximal convoluted tubules $(\mathrm{P})$ with prominent brush border (arrows) and parts of distal convoluted tubules (D) with pale cytoplasm. Toluidine blue $\times 1000$

Figure 6.3. A photomicrograph of a semithin section of the renal cortex of vitamin C-treated rat group showing a glomerular tuft of capillaries $(\mathrm{G})$, proximal convoluted tubules (P), and distal convoluted tubules (D). Toluidine blue, $\times 400$.

Figure 6.4. A photomicrograph of a semithin section of the renal cortex of vitamin C-treated rat group showing; glomerular tuft of capillaries (G), proximal convoluted tubules (P) with prominent brush border (arrow) and distal convoluted tubules (D) with pale cytoplasm, and peritubular blood capillaries (C). Toluidine blue $\times 1000$.

Figure 6.5. A photomicrograph of a semithin section of the renal cortex of nicotine-treated rat group showing partial destruction of cells lining the proximal (P) and distal (D) convoluted tubules, as well as presence of areas desquamated disrupted brush border of proximal convoluted tubules (thin arrows). Densely stained pyknotic nuclei can also be seen (thick arrow), and a collapsed necrotic glomerulus (asterisk). Apparent thickening of the basement membrane of distal convoluted tubule was noticed (arrowhead). Toluidine blue, $\times 400$.

Figure 6.6. A photomicrograph of a semithin section of the renal cortex of nicotine-treated rat group showing dilatation and destruction of cells lining the proximal (P) and distal (D) convoluted tubules, as well as presence of partially desquamated disrupted brush border of proximal convoluted tubules (asterisk). Densely stained 
nuclei can also be seen (arrowheads), and desquamated cells (thin arrows) present inside proximal convoluted tubules. Note the irregular shapes of the nuclei of some tubular cells (thick arrows). Toluidine blue, $\times 1000$.

Figure 6.7. A photomicrograph of a semithin section of the renal cortex of nicotine+vitaminC-treated rat group showing a few dilatation and destruction of some cells lining the proximal (P) and distal (D) convoluted tubules, as well as presence of partially desquamated disrupted brush border of proximal convoluted tubules (asterisk). Many parts of proximal convoluted tubules showed preserved brush border (arrows). Toluidine blue, $\times 400$.

Figure 6.8. A photomicrograph of a semithin section of the renal cortex of nicotine+vitaminC-treated rat group showing mild dilatation and destruction of some cells lining the proximal $(\mathrm{P})$ convoluted tubules that show partially desquamated disrupted brush border (asterisk). Many parts of proximal convoluted tubules showed preserved brush border (thin arrows). Irregular shape of some nuclei can also be seen (thick arrows), and peritubular blood capillaries (C). Toluidine blue, $\times 1000$.

Figure 6.9. A photomicrograph of a paraffin section of the renal cortex from control rat group showing no proliferating cell nuclear antigen (PCNA) immunohistochemical localization in the nuclei of cells of renal glomerulus (G), proximal (P), and distal (D) convoluted tubules. PCNA immunostain counterstained with H\&E, $\times 1000$.

Figure 6.10. A photomicrograph of a paraffin section of the renal cortex from vitamin C-treated rat group showing no proliferating cell nuclear antigen (PCNA) immunohistochemical localization in the nuclei of cells of renal glomerulus $(\mathrm{G})$, proximal $(\mathrm{P})$, and distal (D) convoluted tubules. The nuclei were basophilic and did not stain brown. PCNA immunostain counterstained with H\&E, $\times 1000$.

Figure 6.11. A photomicrograph of a paraffin section of the renal cortex from nicotine-treated rat group showing positive reaction for proliferating cell nuclear antigen (PCNA) immunohistochemical localization in the nuclei of some cells in the renal glomerulus (G), proximal (P), and distal (D) convoluted tubules. The PCNA-positive nuclei were stained brown (arrows). PCNA immunostain counterstained with H\&E, $\times 1000$.

Figure 6.12. A photomicrograph of a paraffin section of the renal cortex from nicotine-treated rat group used to test the specificity of PCNA antibodies and immunohistochemistry. When no primary antibody was applied there was no brown color for PCNA immunostain in the nuclei of the renal glomerulus $(\mathrm{G})$, and proximal (P) convoluted tubules. PCNA immunostain counterstained with H\&E, $\times 1000$.

Figure 6.13. A photomicrograph of a paraffin section of the renal cortex from nicotine+vitamin $\mathrm{C}$-treated rat group showing strong positive reaction for proliferating cell nuclear antigen (PCNA) immunohistochemical localization in the nuclei of some cells in the renal glomerulus $(G)$, proximal (P), and distal (D) convoluted tubules. The PCNA-positive nuclei were intensely stained brown (arrows). PCNA immunostain counterstained with H\&E, $\times 1000$. 